\title{
METAL COMPLEXES OF NOVEL SCHIFF BASE CONTAINING ISATIN: CHARACTERIZATION, ANTIMICROBIAL, ANTIOXIDANT AND CATALYTIC ACTIVITY STUDY
}

\author{
VAIRALAKSHMI $\mathbf{M}^{1,2}$, PRINCESS $\mathbf{R}^{3}$, JOHNSON RAJA $\mathbf{S}^{4 *}$ \\ ${ }^{1}$ Research and Development Centre, Bharathiar University, Coimbatore, Tamil Nadu, India. ${ }^{2}$ Department of Chemistry, V. V. Vanniaperumal \\ College for Women, Virudhunagar, Tamil Nadu, India. ${ }^{3}$ Department of Biotechnology, Mepco Schlenk Engineering College, Sivakasi, \\ Tamil Nadu, India. ${ }^{4}$ Department of Chemistry, American College, Madurai, Tamil Nadu, India. Email: chemjohnson05@gmail.com.
}

Received: 17 May 2019, Revised and Accepted: 26 June 2019

ABSTRACT

Objectives: The aim of our work was to synthesize novel mixed ligand-metal complexes and evaluation of antimicrobial, antioxidant assay, and analysis of catalytic oxidation of cyclohexane.

Methods: The complexes were characterized by means of various physicochemical techniques such as elemental analysis, molar conductance, magnetic susceptibility, infrared (IR), electronic absorption, ${ }^{1} \mathrm{H}$ NMR (proton magnetic resonance), and mass spectral studies. The antimicrobial screening study was done by disc diffusion method. The catalytic activity of the complexes was observed in the oxidation of cyclohexane using ecofriendly hydrogen peroxide as oxidant.

Results: On comparing the ${ }^{1} \mathrm{H}$ NMR and IR spectral data of free ligand and its complexes, it was found to be azomethine (CH=N) proton which is formed in the free ligand. During complexation, the azomethine proton is coordinated to the metal ion and the phenolic oxygen is coordinated to the metal ion by deprotonation. The analytical data and mass spectra of the ligand and the complexes confirm the stoichiometry of metal complexes as being of the (MLY)Cl type and the metal to ligand ratio is $1: 1$. The antimicrobial, antioxidant, and catalytic potential were evaluated and the result shows the better activity of the complexes than the ligand.

Conclusion: It was found to be copper(II) and zinc(II) complexes which are effective against all the bacteria when compared to standard drug streptomycin. Copper(II) complex was found to be effective antibacterial agent against Aspergillus niger and Aspergillus flavus in comparison to the standard drug Nystatin. The zinc complex exhibited good catalytic activity.

Keywords: Antimicrobial activity, Catalytic activity, Mixed ligand-metal complexes, Octahedral geometry, Radical scavenging activity.

(C) 2019 The Authors. Published by Innovare Academic Sciences Pvt Ltd. This is an open access article under the CC BY license (http://creativecommons. org/licenses/by/4. 0/) DOI: http://dx.doi.org/10.22159/ajpcr.2019.v12i8.34189

\section{INTRODUCTION}

The biologically active compound isatin (indole-2,3-dione) was first obtained in 1841 from the oxidation of indigo dye by nitric and chromic acids [1]. In nature, isatin is found in plants and widely distributed in mammalian tissues and body fluids [2]. The biologically active compound isatin's concentration in urine is to become a diagnostic marker for the clinical severity of Parkinson's disease in humans; however, electrophysiology, synthetic, and metabolic pathways of isatin in human system are yet to be fully established. In organic synthesis, isatin and its derivatives have widely used as key intermediate due to their biological and pharmacological properties [1,3]. The multicoordination centers form stable chelates with essential metal ions which, in turn, used in human's metabolism. Salicylaldehyde-based Schiff base metal complexes serve as high potential antibacterial agent [4]. The electrochemical determination of isatin and other nitrogen heterocycles using various electrode systems attains prominence in recent years. The derivatives of isatin were reported to show anti-HIV, anticonvulsant, antibacterial, antifungal, antiprotozoal, antiviral, and antioxidant activities [5-13].

A wide range of molecular disorder accumulated due to oxidative stress is originated as a result of an imbalance between the free radical production and antioxidant defenses [14,15]. Antioxidant acts as scavenger to prevent the damage of cell and tissue. The byproducts of normal metabolisms are $\mathrm{O}_{2}^{-}$and $\mathrm{OH}^{-}$(reactive oxygen species) and are detected in all types of organisms [16]. In addition to phenolic compounds, aromatic heterocyclic amines showed that antioxidant properties in vitro have been discussed from the view of chemical kinetics [17].
Oxidation of cyclohexane is an important industrial reaction. Most of the industries struggle with the manufacture of cyclohexanol and cyclohexanone from cyclohexane at high temperature and pressure. To overcome these difficulties, nowadays, Schiff base metal complexes act as a catalyst toward the oxidation of cyclohexane reaction at low temperature and pressure [18]. The Schiff base derived from isatin possesses significant enhancement antibacterial, antifungal, and antioxidant activities during complexation [19].

Bearing these facts in mind, to enhance the biological and catalytic properties of Schiff base metal complexes, we are planned to synthesis the metal complexes using mixed ligand. In this concerned, the hexacoordinated mixed ligand $\mathrm{Cu}(\mathrm{II}), \mathrm{Zn}(\mathrm{II}), \mathrm{Ni}(\mathrm{II})$, and $\mathrm{Co}(\mathrm{II})$ complexes were synthesized from the diimino-tetradentate Schiff base which was derived from the condensation of isatin with ethylenediamine and bipyridine. These metal complexes showed remarkable antimicrobial and antioxidant activities which may find their importance in medicinal chemistry. The metal complexes also exhibited catalytic activity toward the oxidation of cyclohexane using environmental-friendly hydrogen peroxide as oxidant.

\section{EXPERIMENTAL}

Materials

All chemicals used in the present work, namely, isatin, salicylaldehyde, ethylenediamine, bipyridine, copper, zinc, cobalt, and nickel chlorides were of analytical reagent grade (Merk, Germany). Solvents were purified according to the standard procedures described in Weissenburg series [20] and in quantitative analysis by Vogel [21]. 


\section{Physical measurements}

The elemental analysis (C, H, and N) was performed using a Carlo Erba 1108 analyzer. The molar conductivity of the complex was measured using a Systronics model-304 digital direct reading conductivity meter. Magnetic susceptibility measurements were carried out by employing the Gouy method at room temperature on powder sample of the complex. Infrared (IR) spectra of the Schiff base and its metal complexes were recorded as $\mathrm{KBr}$ discs in the range $400-4000 \mathrm{~cm}^{-1}$ on a Shimadzu spectrophotometer. The electronic absorption spectra of the Schiff base and its metal complexes were recorded on a Shimadzu ultraviolet (UV)1601 spectrophotometer. The proton NMR spectra of the Schiff base and its zinc complex in dimethylsulfoxide (DMSO)- $\mathrm{d}_{6}$ were recorded using tetramethylsilane as internal standard. Electrospray ionization mass spectrometry (ESI-MS) analysis was performed in the positive ion mode on a liquid chromatography-ion trap MS.

\section{Estimation of metal}

The metals were estimated gravimetrically as their oxides [22] by fusion with AnalaR ammonium oxalate. In a typical experiment, about $0.3 \mathrm{~g}$ of the dried complex was accurately weighed in a previously weighed silica crucible. AnalaR ammonium oxalate, roughly three parts by weight of the complex, was added and the mixture was incinerated slowly at first and then strongly using a Bunsen burner for $3 \mathrm{~h}$. It was then cooled in a desiccator and weighed. The procedure was repeated until the final oxide weight was constant. From the weight, the percentage of metal in the complex was calculated.

\section{Determination of chloride content}

The chloride present in the complexes was determined gravimetrically as silver nitrate test [21].

\section{Synthesis of ligand (HL)}

A methanolic solution of ethylenediamine $(0.03 \mathrm{~mol}, 2.01 \mathrm{ml})$ was added dropwise to equimolar solution of isatin ( $0.03 \mathrm{~mol}, 4.414 \mathrm{~g}$ ) and salicylaldehyde $(0.03 \mathrm{~mol}, 3.664 \mathrm{~g})$ in methanol. The reaction mixture was refluxed for ca. $4 \mathrm{~h}$. The resulting precipitate was filtered and recrystallized from methanol and dried in vacuo over silica gel, yield $=87 \%$. The schematic representation of the Schiff base is given in Fig. 1.

\section{Synthesis of metal complexes}

A hot methanolic solution of the Schiff base ligand $(0.003 \mathrm{~mol})$ was added to the methanolic solution of metal(II) chlorides $(0.003 \mathrm{~mol})$ and refluxed for ca. $3 \mathrm{~h}$. To the above mixture, a methanolic solution of bipyridine $(0.003 \mathrm{~mol})$ was added in a 1:1:1 molar ratio and refluxed for about ca. $2 \mathrm{~h}$. The solid product formed was filtered and washed with methanol.

\section{Biological studies}

Antibacterial studies

Antibacterial activity of Schiff base and its complexes was evaluated using disc diffusion concept of the Kirby-Bauer sensitivity test. Human pathogens such as Bacillus subtilis, Staphylococcus aureus, Escherichia coli, and Proteus mirabilis are used in the current study. Nutrient agar was used as a basal medium for the culture of the test bacteria. The agar plates were then inoculated with broth cultures diluted to 0.5 McFarland turbidity $\left(\sim 1.5 \times 10^{8}\right.$ cells $\left./ \mathrm{mL}\right)$. The stock solutions were prepared by dissolving the compounds in appropriate solvents (DMSO). Discs ( $5 \mathrm{~mm}$ diameter and $1 \mathrm{~mm}$ thickness) containing known amounts of an antimicrobial agent were placed on the surface of an agar plate that has been inoculated with a standardized suspension of

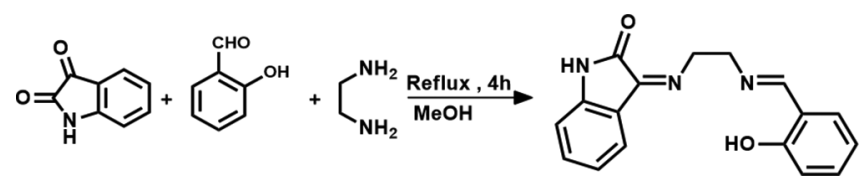

Fig. 1: Synthesis of the Schiff base microorganisms to be tested. Paper discs with only DMSO were used as negative controls. Then, the plates were incubated at $37^{\circ} \mathrm{C}$ for $24 \mathrm{~h}$. During this period, the test solution diffused and affected the growth of the inoculated bacteria. The susceptibility of bacterial species was determined by the diameter of zone of inhibition (in millimeter) [23]. Streptomycin was used as standard.

\section{Antifungal studies}

The in vitro antifungal screening of the Schiff base and its complexes was evaluated by the disc diffusion method [24] against the fungi such as Aspergillus niger, Aspergillus flavus, Rhizoctonia bataticola, and Candida albicans. Potato dextrose agar was used as medium for the evaluation of antifungal activity. For preparing the agar media, $200 \mathrm{~g}$ of potato extract, $20 \mathrm{~g}$ of agar, and $20 \mathrm{~g}$ of dextrose were dissolved in $1000 \mathrm{~mL}$ of distilled water in a clean conical flask. The solution was boiled to dissolve the medium completely and sterilized by autoclaving at 15 psi pressure $\left(120^{\circ} \mathrm{C}\right)$ for $30 \mathrm{~min}$. After sterilization, $20 \mathrm{~mL}$ of media was poured into the sterilized Petri plates. These Petri plates were kept at room temperature for sometimes. After few minutes, the medium got solidified in the plates. Then, it was inoculated with microorganisms using sterile swabs. The $5 \mathrm{~mm}$ diameter and $1 \mathrm{~mm}$ thickness of the disc were filled with the test solution $(100 \mu \mathrm{g} / \mathrm{ml})$ using a micropipette and the plates were incubated at $37^{\circ} \mathrm{C}$ for $72 \mathrm{~h}$. During this period, the test solution diffused and affected the growth of the inoculated fungi. After $72 \mathrm{~h}$ of incubation at $37^{\circ} \mathrm{C}$, the diameter of the zone of inhibition was measured [23]. Nystatin was used as standard.

\section{Antioxidant studies (1,1-diphenyl-2-picrylhydrazyl [DPPH] assay)}

The evaluation of antioxidant activity of newly synthesized compounds was done by DPPH radical scavenging activity assay [25]. Different concentrations $(100,50,25$, and $12.5 \mu \mathrm{g} / \mathrm{ml})$ of Schiff base metal complexes were weighed respectively and dissolved in DMSO. Then, $5 \mathrm{ml}$ of $0.1 \mathrm{mM}$ methanolic solution of DPPH was added to each of the test tube containing the sample and the tubes were shaken vigorously. They were then allowed to stand at room temperature for $30 \mathrm{~min}$. The control was prepared without any compound and methanol was used for baseline corrections in absorbance odds ratios of samples measured at $517 \mathrm{~nm}$. For each concentration, the decrease in the absorbance was recorded and percentage quenching of DPPH was calculated. The radical scavenging activities were expressed as percentage scavenging activity and were calculated by the following formula.

$\%$ Radical scavenging activity $=\frac{\text { Control OD }- \text { Sample OD }}{\text { Control OD }} \times 100$

\section{Catalytic activities}

The oxidation of cyclohexane has always been an area of intensive research because it is one of the essential steps in the production of nylon. The catalytic oxidation of cyclohexane was carried out in acetonitrile solvent using hydrogen peroxide as an oxidant in the presence of mixed ligand-metal complex [MLY]Cl as catalyst. In a typical reaction, about $0.1 \mathrm{~mol}_{2} \mathrm{O}_{2}$ was added to the mixture of $0.1 \mathrm{~mol}$ cyclohexane and $0.001 \mathrm{~mol}$ [MLY]Cl in acetonitrile and the reaction mixture was stirred for $5 \mathrm{~h}$ at $343 \mathrm{~K}$. The reaction progress and its completion were checked by analyzing the reaction mixture using thin-layer chromatography by withdrawing small aliquots of the reaction mixture at specific interval of time. The percentage yield of the products was noted.

\section{RESULTS AND DISCUSSION}

\section{Analytical studies}

The complexes of the type [MLY]Cl where, $\mathrm{M}=\mathrm{Cu}(\mathrm{II}), \mathrm{Zn}(\mathrm{II}), \mathrm{Ni}(\mathrm{II})$, and Co(II), L=tetradentate Schiff base, and Y=bipyridine were synthesized by the reaction of tetradentate ligand, metal(II) chlorides, and bipyridine in a 1:1:1 molar ratio in methanol. In DMSO, the complexes showed higher molar conductance value indicates the electrolytic nature. 


\section{IR spectra}

The IR spectrum of the free ligand showed a band at $1618 \mathrm{~cm}^{-1}$ which can be attributed to azomethine moiety. This band is shifted to lower frequency around $1606-1598 \mathrm{~cm}^{-1}$ in the spectra of complexes which indicate the coordination of metal to the azomethine nitrogen. The absorption band appeared at $1757 \mathrm{~cm}^{-1}$ is due to $v \mathrm{C}=0$. This band shifted to lower wavenumber in the complexes indicates involvement of $v \mathrm{C}=0$ with metal center during complexation. The ligand showed that a band at $3400 \mathrm{~cm}^{-1}$ is due to phenolic $\mathrm{OH}$ group. The absence of $v \mathrm{OH}$ band in all the complexes suggests subsequent deprotonation of phenolic group and coordination of phenolic oxygen to the metal ion. The band at $3160 \mathrm{~cm}^{-1}$ in the spectrum of free ligand assigned to $v \mathrm{~N}-\mathrm{H}$ stretching vibration. The position of this band remains nearly the same frequency in the spectra of metal complexes suggesting the uncoordination of this group [26]. The band at $1280 \mathrm{~cm}^{-1}$ is due to phenolic C-O. This band shifted to lower wavenumber in the complexes indicates coordination of metal to the phenolic $\mathrm{C}-0$. The appearance of two new bands in the regions $545-525 \mathrm{~cm}^{-1}$ and $459-422 \mathrm{~cm}^{-1}$ in the spectra of complexes was due to $v \mathrm{M}-\mathrm{N}$ and $v \mathrm{M}-0$ stretching vibrations, respectively [27].

\section{Electronic absorption spectra and magnetic measurement}

The electronic spectra of ligand and its complexes were recorded in methanol. The ligand shows two bands at 40323 and $32787 \mathrm{~cm}^{-1}$ assigned for $\pi \pi^{*}$ and $n \pi^{*}$ electronic transitions, respectively [28]. Nickel(II) complex exhibits three bands at 12,919, 15,924, and $20,833 \mathrm{~cm}^{-1}$ attributed to $^{3} \mathrm{~A}_{2 \mathrm{~g}}$ (F) $\rightarrow{ }^{3} \mathrm{~T}_{2 \mathrm{~g}}(\mathrm{~F}),{ }^{3} \mathrm{~A}_{2 \mathrm{~g}}$ (F) $\rightarrow{ }^{3} \mathrm{~T}_{1 \mathrm{~g}}(\mathrm{~F})$, and $\mathrm{A}_{2 \mathrm{~g}}(\mathrm{~F}) \rightarrow{ }^{3} \mathrm{~T}_{1 \mathrm{~g}}(\mathrm{P})$ transitions indicating octahedral geometry. The nickel(II) complex showed magnetic moment value of 3.14 B.M corresponding to two unpaired electrons in an octahedral environment [29]. Copper complex shows a band at $16,556 \mathrm{~cm}^{-1}$ assigned for ${ }^{2} \mathrm{E}_{\mathrm{g}} \rightarrow{ }^{2} \mathrm{~T}_{\mathrm{g}}$ transition suggesting a distorted octahedral geometry [30] which was further supported by its magnetic moment value of 1.88 B.M. The cobalt(II) complex exhibits two bands at 33,003 and $21,368 \mathrm{~cm}^{-1}$ assigned to ${ }^{4} \mathrm{~T}_{1 \mathrm{~g}}(\mathrm{~F}) \rightarrow{ }^{4} \mathrm{~T}_{1 \mathrm{~g}}(\mathrm{P})$ and ${ }^{4} \mathrm{~T}_{1 \mathrm{~g}}(\mathrm{~F}) \rightarrow{ }^{4} \mathrm{~A}_{2 \mathrm{~g}}$ transitions. The magnetic moment value of Co(II) complex was 4.86 B.M., which favors octahedral geometry [31]. Zn(II) complex does not show d-d transition due to its diamagnetic nature [32].

\section{Proton magnetic resonance spectra}

The proton magnetic resonance spectra of ligand and its $\mathrm{Zn}$ (II) complex were recorded in DMSO- $\mathrm{d}_{6}$. The ${ }^{1} \mathrm{H}$ NMR spectrum of ligand and its zinc(II) complex exhibited signals at $10.3 \mathrm{ppm}$ and $2.6 \mathrm{ppm}$ due to $\mathrm{NH}$ proton of isatin moiety [33] and $\mathrm{N}-\mathrm{CH}_{2}$ protons [34]. The phenyl multiplet appeared at $6.8-7.2 \mathrm{ppm}$. The spectrum of the free ligand exhibited a signal at $13.3 \mathrm{ppm}$ due to phenolic protons [35]. The azomethine $(\mathrm{CH}=\mathrm{N})$ proton appeared as a singlet at $8.43 \mathrm{ppm}$. However, in the spectrum of zinc(II) complex, the azomethine $(\mathrm{CH}=\mathrm{N})$ proton showed a downfield shift at $8.9 \mathrm{ppm}$, thereby suggesting the coordination of imino nitrogen to zinc ion. In the $\mathrm{Zn}$ (II) complex, the phenolic proton was disappeared indicating the coordination of these to $\mathrm{Zn}(\mathrm{II})$ ion by deprotonation. The signals at 7.60-7.76 and 8.20-8.39 ppm were assigned to bipyridine protons. The proton magnetic resonance spectra of the ligand and its zinc complex are given in Figs. 2 and 3.

\section{Mass spectra}

The ESI mass spectra of the ligand and its Zn(II) complex were recorded and the obtained molecular ion peak confirmed the proposed formulae. The mass spectrum of the ligand exhibited peak $\mathrm{m} / \mathrm{z}$ at $293\left(\mathrm{M}^{+}\right)$with $100 \%$ abundance which was also confirmed by "nitrogen rule." The mass spectrum of Zinc(II) complex showed a molecular ion peak $\mathrm{m} / \mathrm{z}$ at 549 which is equivalent to its molecular weight and also exhibited two additional peaks $\mathrm{m} / \mathrm{z}$ at 550 and 551 , which are corresponding to $(M+1)$ and $(M+2)$ peaks, respectively.

Based on the elemental analysis, molar conductance, magnetic moments, IR, UV-Vis., proton NMR, and mass spectral data, the proposed structure of the complexes is given in Fig. 4.

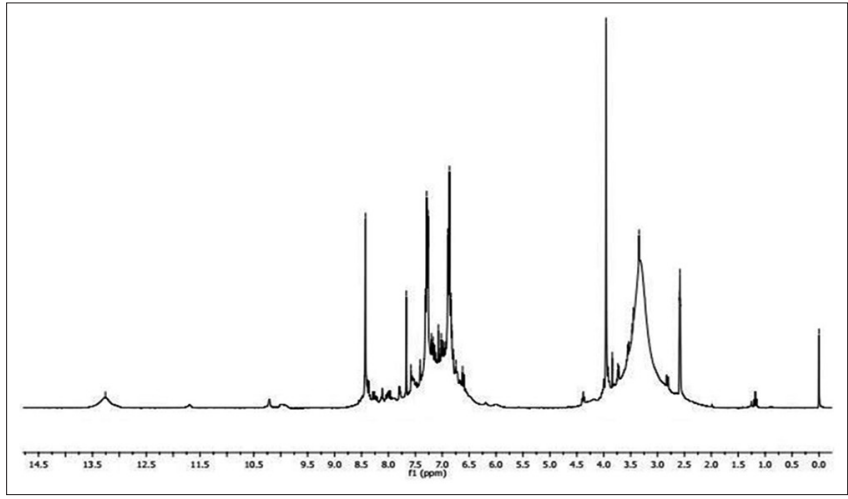

Fig. 2: ${ }^{1} \mathrm{H}$ NMR spectra of ligand

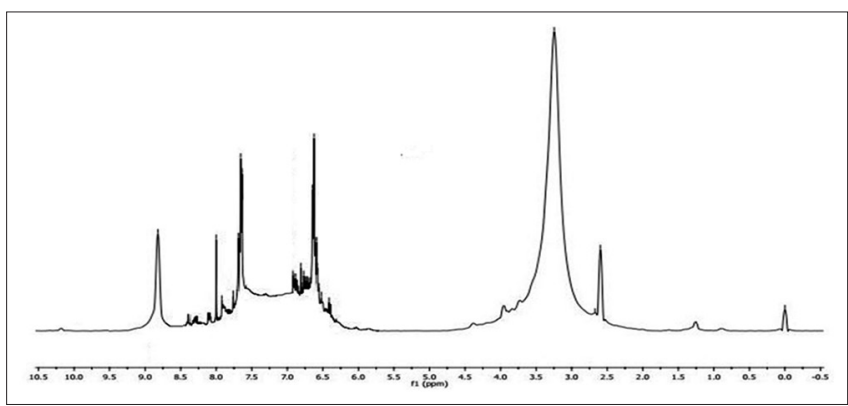

Fig. 3: ${ }^{1} \mathrm{H}$ NMR spectra of $[\mathrm{ZnLY}] \mathrm{Cl}$

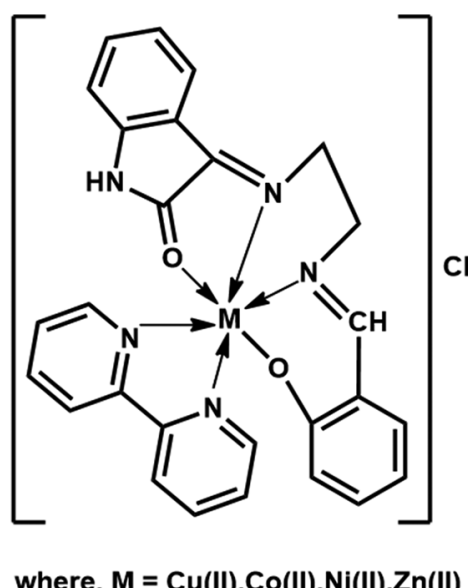

Fig. 4: Structure of synthesized complexes

\section{Antibacterial studies}

The antibacterial efficacy of the ligand and its metal complexes was tested against the human pathogens such as B. subtilis, S. aureus, E. coli, and P. mirabilis. Three different concentrations $(25 \mu \mathrm{g} / \mathrm{ml}$, $50 \mu \mathrm{g} / \mathrm{ml}$, and $75 \mu \mathrm{g} / \mathrm{ml}$ ) of the compounds have been tested for antibacterial assay. The results are presented in Table 1. The results of the antibacterial activity showed that all the complexes possess good activity against $B$. subtilis, $S$. aureus, E. coli, and P. mirabilis. The $\mathrm{Cu}(\mathrm{II})$ and Zn(II) complexes exhibited enhanced activity against all the bacteria examined than the standard drug streptomycin. The enhanced activity of the complexes may be attributed to chelation of Schiff base with metal ion [36]. The partial sharing of positive charge with the donor groups and possible $\pi$-electron delocalization within the chelate ring system makes the metal ion as less polar. Due to this reduced polarity of the metal ion, the lipophilicity of the complex increases, and hence, diffusion of metal ion through cell membrane becomes easier. Thus, chelating effect makes the metal complex as powerful antibacterial 
Table 1: Antibacterial activity of ligand and its metal(II) complexes (zone of inhibition in mm)

\begin{tabular}{|c|c|c|c|c|c|c|}
\hline \multirow[t]{3}{*}{ Compound } & \multicolumn{6}{|c|}{ Gram-positive bacteria } \\
\hline & \multicolumn{3}{|c|}{ B. subtilis } & \multicolumn{3}{|c|}{ S. aureus } \\
\hline & $25(\mu \mathrm{g})$ & $50(\mu \mathrm{g})$ & $75(\mu \mathrm{g})$ & $25(\mu \mathrm{g})$ & $50(\mu \mathrm{g})$ & $75(\mu \mathrm{g})$ \\
\hline HL & $8 \pm 0.4$ & $11 \pm 0.55$ & $13 \pm 0.65$ & $13 \pm 0.65$ & $15 \pm 0.75$ & $17 \pm 0.85$ \\
\hline [CuLY]Cl & $21 \pm 1.05$ & $24 \pm 1.2$ & $28 \pm 1.4$ & $25 \pm 1.25$ & $27 \pm 1.35$ & $28 \pm 1.4$ \\
\hline [ZnLY]Cl & $17 \pm 0.85$ & $20 \pm 1$ & $23 \pm 1.15$ & $20 \pm 1$ & $23 \pm 1.15$ & $26 \pm 1.3$ \\
\hline [NiLY]Cl & $13 \pm 0.65$ & $14 \pm 0.7$ & $17 \pm 0.85$ & $16 \pm 0.8$ & $17 \pm 0.85$ & $18 \pm 0.9$ \\
\hline Streptomycin & $13 \pm 0.65$ & $15 \pm 0.75$ & $20 \pm 1$ & $18 \pm 0.9$ & $22 \pm 1.1$ & $24 \pm 1.2$ \\
\hline \multirow[t]{3}{*}{ Compound } & \multicolumn{6}{|c|}{ Gram-negative bacteria } \\
\hline & \multicolumn{3}{|l|}{ E. coli } & \multicolumn{3}{|c|}{ P. mirabilis } \\
\hline & $25(\mu \mathrm{g})$ & $50(\mu \mathrm{g})$ & $75(\mu \mathrm{g})$ & $25(\mu \mathrm{g})$ & $50(\mu \mathrm{g})$ & $75(\mu \mathrm{g})$ \\
\hline HL & $17 \pm 0.85$ & $19 \pm 0.95$ & $21 \pm 1.05$ & $9 \pm 0.45$ & $12 \pm 0.6$ & $13 \pm 0.65$ \\
\hline [CuLY]Cl & $24 \pm 1.2$ & $26 \pm 1.3$ & $30 \pm 1.5$ & $10 \pm 1.35$ & $28 \pm 1.4$ & $31 \pm 1.55$ \\
\hline [NiLY]Cl & $21 \pm 1.05$ & $22 \pm 1.1$ & $28 \pm 1.25$ & $12 \pm 0.65$ & $15 \pm 0.75$ & $17 \pm 0.85$ \\
\hline [CoLY]Cl & $20 \pm 1$ & $22 \pm 1.1$ & $29 \pm 1.2$ & $13 \pm 0.6$ & $13 \pm 0.65$ & $15 \pm 0.75$ \\
\hline Streptomycin & $22 \pm 1.1$ & $23 \pm 1.15$ & $30 \pm 1.3$ & $14 \pm 0.75$ & $18 \pm 0.9$ & $20 \pm 1$ \\
\hline
\end{tabular}

*All the experiments were repeated independently 3 times and the values were represented as an average mean \pm standard deviation. E. coli: Escherichia coli, P. mirabilis: Proteus mirabilis, B. subtilis: Bacillus subtilis, S. aureus: Staphylococcus aureus

Table 2: Antifungal activity of ligand and its metal(II) complexes

\begin{tabular}{lllll}
\hline Compound & \multicolumn{4}{l}{ Zone of inhibition in $\mathbf{~ m m}$} \\
\cline { 2 - 5 } & A. niger & A. flavus & R. bataticola & C. albicans \\
\hline HL & $7 \pm 0.35$ & $5 \pm 0.25$ & $6 \pm 0.3$ & $9 \pm 0.45$ \\
{$[$ CuLY]Cl } & $15 \pm 0.75$ & $13 \pm 0.65$ & $10 \pm 0.5$ & $14 \pm 0.7$ \\
{$[\mathrm{ZnLY}] \mathrm{Cl}$} & $12 \pm 0.6$ & $7 \pm 0.35$ & $9 \pm 0.45$ & $13 \pm 0.65$ \\
{$[\mathrm{NiLY}] \mathrm{Cl}$} & $10 \pm 0.5$ & $7 \pm 0.35$ & $6 \pm 0.3$ & $12 \pm 0.6$ \\
{$[$ CoLY]Cl } & $9 \pm 0.45$ & $10 \pm 0.5$ & $7 \pm 0.35$ & $10 \pm 0.5$ \\
Nystatin & $14 \pm 0.7$ & $12 \pm 0.6$ & $13 \pm 0.65$ & $16 \pm 0.8$ \\
\hline
\end{tabular}

*All the experiments were repeated independently 3 times and the values were represented as an average mean \pm standard deviation. A. niger: Aspergillus niger A. flavus: Aspergillus flavus, R. bataticola: Rhizoctonia bataticola, C. albicans: Candida albicans

agents and thereby inhibits the growth of microorganisms or destroys the microbes due to blocking their active sites.

\section{Antifungal studies}

The antifungal activity was carried out by disc diffusion method. The ligand and its $\mathrm{Cu}(\mathrm{II}), \mathrm{Zn}(\mathrm{II}), \mathrm{Ni}(\mathrm{II})$, and $\mathrm{Co}(\mathrm{II})$ complexes have been tested for their antifungal activity at $100 \mu \mathrm{g} / \mathrm{ml}$ concentration. The results are shown in Table 2. The results showed that copper complex exhibits enhanced activity against $A$. niger and A. flavus than the standard drug nystatin and it showed moderate effect on $R$. bataticola and $C$. albicans. In this regard, copper and zinc complexes exhibited good activity against A. niger, A. flavus, $R$. bataticola, and $C$. albicans. Nickel and cobalt complexes exhibited moderate activity against niger, A. flavus, R. bataticola, and C. albicans.

\section{Antioxidant studies}

The capability of DPPH to receive an electron or hydrogen from antioxidant molecule makes it become a stable diamagnetic molecule $[37,38]$. The antioxidant assay is a dynamic method to anticipate the scavenging ability of metal complexes, tested with respect to different concentrations $(100,50,25$, and $12.5 \mu \mathrm{g} / \mathrm{ml})$ of $\mathrm{Cu}(\mathrm{II}), \mathrm{Zn}(\mathrm{II}), \mathrm{Ni}(\mathrm{II})$, and $\mathrm{Co}(\mathrm{II})$ metal complexes with DPPH radical. The data revealed that $\mathrm{Cu}(\mathrm{II})$ and $\mathrm{Zn}(\mathrm{II})$ complexes exhibited potent antioxidant activity even in minimum concentration $(12.5 \mu \mathrm{g} / \mathrm{ml})$ level than the $\mathrm{Ni}(\mathrm{II})$ and $\mathrm{Co}(\mathrm{II})$ complexes. The free radical scavenging ability of the metal complexes is presented in Table 3.
Table 3: Antioxidant activity metal(II) complexes

\begin{tabular}{lllll}
\hline \multirow{2}{*}{ Concentration } & \multicolumn{4}{c}{ \% of radical scavenging activity } \\
\cline { 2 - 5 } & [CuLX] & [ZnLX] & [NiLX] & [CoLX] \\
\hline $100 \mu \mathrm{g} / \mathrm{ml}$ & 71.3 & 57.1 & 50.4 & 69.5 \\
$50 \mu \mathrm{g} / \mathrm{ml}$ & 60.1 & 48.0 & 41.3 & 58.3 \\
$25 \mu \mathrm{g} / \mathrm{ml}$ & 49.5 & 39.2 & 32.0 & 47.1 \\
$12.5 \mu \mathrm{g} / \mathrm{ml}$ & 39.0 & 27.5 & 24.6 & 36.3 \\
$\mathrm{IC}_{50}(\mu \mathrm{M})$ & 48.4 & 123.8 & 183.9 & 59.6 \\
\hline
\end{tabular}

Table 4: Catalytic oxidation of cyclohexane by [MLY]Cl

\begin{tabular}{lll}
\hline Compound & \multicolumn{2}{l}{ Products (\% yield) } \\
\cline { 2 - 3 } & Cyclohexanol & Cyclohexanone \\
\hline$[\mathrm{CuLY}] \mathrm{Cl}$ & 31.4 & 10.1 \\
{$[\mathrm{ZnLY}] \mathrm{Cl}$} & 35.3 & 11 \\
{$[\mathrm{NiLY}] \mathrm{Cl}$} & 27.5 & 9.5 \\
{$[\mathrm{CoLY}] \mathrm{Cl}$} & 29.6 & 9.3 \\
\hline
\end{tabular}

\section{Catalytic activities}

The catalytic activities of the synthesized metal complexes were examined for their activity toward the oxidation of cyclohexane using $\mathrm{H}_{2} \mathrm{O}_{2}$ as the oxidant in $\mathrm{CH}_{3} \mathrm{CN}$. The major and minor products were found to be cyclohexanol and cyclohexanone, respectively. No significant amount of adipic acid was obtained. In the absence of catalyst, no oxidation products were produced. This indicates that hydrogen peroxide alone is unable to oxidize cyclohexane. The results are given in Table 4.

\section{CONCLUSION}

In this work, a new series of novel Schiff base ligand and its metal complexes of $\mathrm{Cu}(\mathrm{II}), \mathrm{Zn}(\mathrm{II}), \mathrm{Ni}(\mathrm{II})$, and $\mathrm{Co}(\mathrm{II})$ were reported and their potential of antimicrobial, antioxidant, and catalytic activity was also explored. The structure of these complexes was investigated by UVVis., IR, proton NMR, and mass spectral studies and they exposed the octahedral nature of the complexes. The high molar conductance value revealed the electrolytic nature of the complexes. The antibacterial and antifungal activities of the free ligand and its complexes showed efficient biocidal and fungicidal activity. Copper and zinc complexes 
exhibited efficient biocidal activity compared to the free ligand and other complexes even than the standard drug streptomycin. Copper complex exhibited enhanced activity against $A$. niger and A. flavus than the standard drug nystatin. It was found that all the complexes are good potential antioxidants. Especially, $\mathrm{Cu}$ (II) and Zn(II) complexes possessed enhanced antioxidant activity. The catalytic activity of the synthesized mixed ligand-metal complexes was tested in the cyclohexane oxidation reaction using $\mathrm{H}_{2} \mathrm{O}_{2}$ as oxidant. It was found to be zinc complex exhibits good catalytic activities than the other complexes.

\section{AUTHORS' CONTRIBUTIONS}

The authors wish to thank the Bharathiar University for the approval of research program. The author MV thanks to the Management, Principal of V. V. Vanniaperumal College for Women for their keen interest and constant encouragement throughout this investigation. The author SJ thanks to the management, Principal of PSR Engineering College for their support.

\section{CONFLICTS OF INTEREST}

The authors declare that there are no conflicts of interest concerning the publication of this paper.

\section{REFERENCES}

1. da Silva JF, Garden SJ, Pinto AC. The chemistry of isatins: A review from 1975 to1999. J Braz Chem Soc 2001;12:273-324.

2. Medvedev AE, Clow A, Sandler M, Glover V. Isatin: A link between natriuretic peptides and monoamines? Biochem Pharmacol 1996;52:385-91.

3. Pushpa H, Naraboli BS, Biradar SJ. Synthesis, characterization, and biological activity of novel N-phenylpropyl-3-substituted indoline-2one derivatives. Int J Pharm Pharm Sci 2017;9:165-70.

4. Farhana A, Sadia AD, Hossain MS, Sarker MS. Synthesis, spectral and thermal characterization of selected metal complexes containing Schiff base ligands with antimicrobial activities. Asian J Chem Sci 2018;4:1-19.

5. Pandeya SN, Sriram D, Nath G, De Clercq E. Synthesis, antibacterial, antifungal and anti-HIV activities of norfloxacin mannich bases. Eur J Med Chem 2000;35:249-55

6. Pandeya SN, Sriram D, Nath G, De Clercq E. Synthesis, antimicrobial and antioxidant activities of mannich bases derived from $1 \mathrm{~h}$-indole-2,3dione and 3-amino-2-phenylquinazol-4-One. Arzneimittelforsch Drug Res 2000;50:55-9.

7. Sridhar SK, Pandeya SN, Stables JP, Ramesh A. Anticonvulsant activity of hydrazones, schiff and mannich bases of isatin derivatives. Eur J Pharm Sci 2002;16:129-32.

8. Pandeya SN, Sriram D. Synthesis and screening for antibacterial activity of Schiff's and mannich bases of isatin and its derivatives. Acta Pharm Turc 1998;16:33-8.

9. Vasanthi R, Sundar PS, Ramana H, Rao KN. Synthesis, characterization and antimicrobial evaluation of some novel 3-hydrazone-1hbenzoindol2(3h)-ones. Indo Am J Pharm Sci 2017;4:3859-63.

10. Saranyaa K, Lakshmia SS, Mahadevia P, Logesh G. Ternary transition metal complexes of tridentate (ONO) Schiff base: Synthesis, spectroscopic and biological studies. J Chem Pharm Res 2015;7:851-8.

11. Javad A, Masoud S, Farhad HM, Reza M. One-pot rapid and efficient synthesis of new spiro derivatives of $11 \mathrm{H}$-indeno[1,2- b]quinoxalin11-one, 6H-indeno[1,2-b]pyrido[3,2-e]pyrazin-6-one and isatin-based 2-pyrazolines. ARKIVOC 2006; 11:47-58.

12. Vijay Kumar H, Naik N. Synthesis and antioxidant properties of some novel $5 \mathrm{H}$-dibenz[b,f]azepine derivatives in different in vitro model systems. Eur J Med Chem 2010;45:2-10.

13. Kumar HV, Kumar CK, Nagaraja N. Synthesis of novel 3-chloro-1(5H-dibenz $[\mathrm{b}, \mathrm{f}]$ azepine-5yl)propan-1-one derivatives with antioxidant activity. Med Chem Res 2011;20:101-8.
14. Lobo V, Patil A, Phatak A, Chandra N. Free radicals, antioxidants and functional foods: Impact on human health. Pharmacogn Rev 2010;4:118-26.

15. Amin S, Parle A. Synthesis, characterization and antioxidant activity of 2-aryl benzothiazole derivatives. Int J Curr Pharm Res 2018;10:3-8.

16. Vipin N, Archana G, Dinesh K. Isolation and characterization of endophytic fungi from Calotropis procera for their antioxidant activity. Asian J Pharm Clin Res 2017;10:254-8.

17. Lucarini M, Pedrielli P, Pedulli GF, Valgimigli L, Gigmes D, Toroda P. Bond dissociation energies of the N-H bond and rate constants for the reaction with alkyl, alkoxyl and peroxyl radicals of phenothiazines and related compounds. J Am Chem Soc 1999;21:11546-33.

18. Zhou LP, Xu J, Miao H, Wang F, Li X. Catalytic oxidation of cyclohexane to cyclohexanol and cyclohexanone over $\mathrm{Co}_{3} \mathrm{O}_{4}$ nanocrystals with molecular oxygen. Appl Catal A Gen 2005;292:223-8.

19. Biyala MK, Fahmi N, Singh RV. Antifertility and antimicrobial activities of palladium and platinum complexes of 6-nitro-3-(indolin-2one) hydrazine carbothiamide and 6-nitro-3-indolin-2-one) hydrazine carboxamide. Indian J Chem 2006;45:1999-2005.

20. Weissenberger A, Proskauer ES, Riddick JA, Toops EE. Organic Solvents: Physical Properties and Methods of Purification Techniques of Organic Chemistry. $3^{\text {rd }}$ ed. New York: Inter Science; 1955.

21. Vogel AI. Practical Organic Chemistry. $4^{\text {th }}$ ed. London: Longman; 1978.

22. Angellici RJ. Synthesis and Techniques in Inorganic Chemistry. $1^{\text {st }}$ ed. Philadelphia, PA: WB Saunders Company; 1969.

23. Pelczar MJ, Chan EC, Krieg NR. Microbiology. $5^{\text {th }}$ ed. New York: McGraw-Hill Inc.; 1998.

24. Kannan N. Laboratory Manual in Microbiology. $1^{\text {st }}$ ed. Palani: Paramount Publication; 1996.

25. Blois MS. Antioxidant determinations by the use of a stable free radical. Nature 1958;26:1199-200.

26. Raman N, Sobha S. Synthesis, characterization, DNA interaction and antimicrobial screening of isatin-based polypyridyl mixed- ligand $\mathrm{Cu}(\mathrm{II})$ and $\mathrm{Zn}(\mathrm{II})$ complexes. J Serb Chem Soc 2010;75:773-88.

27. Bellamy LJ. Infrared Spectra of Complex Molecules. $2^{\text {nd }}$ ed. London: Mathuen; 1958.

28. Neelakantan MA, Marriappan SS, Dharmaraja J, Jeyakumar T, Muthukumaran K. Spectral, XRD, SEM and biological activities of transition metal complexes of polydentate ligands containing thiazole moiety. Spectrochim Acta A Mol Biomol Spectrosc 2008;71:628-35.

29. Lever AB. Inorganic Electronic Spectroscopy. $2^{\text {nd }}$ ed. Amsterdam: Elsevier; 1984

30. Kumar DS, Gandhi SR, Sheriff AK. Synthesis, specterial characterization and antimicrobial activity of bidendate Schiff base (N2) transition metal complexes. J Chem Pharm Res 2015;215:416-23.

31. Antonio C, Massabni P, Corbi PP, Melnikov P, Zacharias A, Rechenberg R. Four new metal complexes with the amino acid deoxyalliin. J Braz Chem Soc 2005;16:718-22.

32. Hassaan MA. Co (II) and Fe (III) complexes of Schiff bases derived from isatin with some amino acids. J Islam Acad Sci 1991;4:271-4.

33. Salehzadeh S, Javarsineh SA, Keypour H. Metal complexes of a new potentially heptadentate $\left(\mathrm{N}_{7}\right)$ tripodal Schiff base ligand: Synthesis, NMR studies and ab initio calculations. J Mol Struct 2006;785:54-62.

34. Pal SD, Vidhi G, Kishan K, Kiran J. Synthesis and characterization of divalent metal complexes of the macrocyclic ligand derived from isatin and 1,2-diaminobenzene. J Serb Chem Soc 2011;76:385-93

35. Bayoumi A, Alaghaz MA, Aljahdali M. Cu(II), Ni(II), Co(II) and Cr(III) complexes with $\mathrm{N}_{2} \mathrm{O}_{2}$ chelating Schiff's base ligand incorporating azo and sulfonamide moieties: Spectroscopic, electrochemical behavior and thermal decomposition studies. Int J Electrochem Sci 2018;8:9399-413.

36. Brown NM, Nonhebel DC. NMR spectra of intramolecularly hydrogen-bonded compounds II: Schiff bases of $\beta$-diketones and o-hydroxycarbonyl compounds. Tetrahedron 1968;24:5655-64.

37. Soares JR, Dinis TC, Cunha AP, Almeida LM. Antioxidant activities of some extracts of Thymus zygis. Free Radic Res 1997;26:469-78.

38. Puri K, Habbu V, Kulkarni V, Kulkarni H. Characterization, in vitro antioxidant and hepatoprotective activity of fungal endophytic extracts of Andrographis paniculata leaves in $\mathrm{CCl}_{4}$ induced hepatotoxicity. Int $\mathrm{J}$ Pharm Pharm Sci 2019;11:44-54. 